\title{
Patient-Reported Satisfaction and Study Drug Discontinuation: Post-Hoc Analysis of Findings from ROCKET AF
}

Leo Ungar · Fatima Rodriguez • Anne S. Hellkamp • Richard C. Becker ·

Scott D. Berkowitz - Guenter Breithardt - Keith A. A. Fox - Werner Hacke

Jonathan L. Halperin · Graeme J. Hankey · Christopher C. Nessel · Daniel E. Singer •

Manesh R. Patel · Jonathan P. Piccini · Kenneth W. Mahaffey

Received: June 24, 2019 / Published online: August 2, 2019

(C) The Author(s) 2019

\section{ABSTRACT}

Introduction: Patient-reported

outcomes

(PROs) and satisfaction endpoints are increasingly important in clinical trials and may be associated with treatment adherence. In this post hoc substudy from ROCKET $\mathrm{AF}$, we

Enhanced Digital Features To view enhanced digital features for this article go to https://doi.org/10.6084/ m9.figshare.9070658.

Electronic supplementary material The online version of this article (https://doi.org/10.1007/s40119019-00146-6) contains supplementary material, which is available to authorized users.

L. Ungar $(\square)$

University of California Irvine Medical Center,

Orange, CA, USA

e-mail: lungar@uci.edu

F. Rodriguez · K. W. Mahaffey

Stanford Center for Clinical Research, Stanford

University School of Medicine, Stanford, CA, USA

A. S. Hellkamp · M. R. Patel · J. P. Piccini

Duke Clinical Research Institute, Duke University

School of Medicine, Durham, NC, USA

R. C. Becker

University of Cincinnati College of Medicine,

Cincinnati, OH, USA

S. D. Berkowitz

Bayer U.S. LLC, Parsippany, NJ, USA examined whether patient-reported satisfaction was associated with study drug discontinuation. Methods: ROCKET AF $(n=14,264)$ compared rivaroxaban with warfarin for prevention of stroke and systemic embolism in patients with atrial fibrillation. We analyzed treatment satisfaction scores: the Anti-Clot Treatment Scale (ACTS) and Treatment Satisfaction Questionnaire for Medication version II (TSQM II). We compared satisfaction with study drug between the two treatment arms, and examined the association between satisfaction and patientdriven study drug discontinuation (stopping study drug due to withdrawal of consent, noncompliance, or loss to follow-up).

\section{G. Breithardt}

Hospital of the University of Münster, Münster, Germany

\section{K. A. A. Fox}

University of Edinburgh and Royal Infirmary of Edinburgh, Edinburgh, UK

W. Hacke

Ruprecht-Karls-University, Heidelberg, Germany

J. L. Halperin

Mount Sinai School of Medicine, New York, NY, USA

G. J. Hankey

School of Medicine and Pharmacology, The

University of Western Australia, Crawley, Australia 
Results: A total of 1577 (11\%) patients participated in the Patient Satisfaction substudy; 1181 (8.3\%) completed both the ACTS and TSQM II 4 weeks after starting study drug. Patients receiving rivaroxaban did not experience significant differences in satisfaction compared with those receiving warfarin. During a median follow-up of 1.6 years, 448 premature study drug discontinuations occurred (213 rivaroxaban group; 235 warfarin group), of which 116 (26\%) were patient-driven (52 [24\%] rivaroxaban group; 64 [27\%] warfarin group). No significant differences were observed between satisfaction level and rates of patient-driven study drug discontinuation.

Conclusions: Study drug satisfaction did not predict rate of study drug discontinuation. No significant difference was observed between satisfaction with warfarin and rivaroxaban, as expected given the double-blind trial design. Although these results are negative, the importance of PRO data will only increase, and these analyses may inform future studies that explore the relationship between drug-satisfaction PROs, adherence, and clinical outcomes.

ClinicalTrials.gov: NCT00403767.

Funding: The ROCKET AF trial was funded by Johnson \& Johnson and Bayer.

Keywords: Anticoagulant; Atrial fibrillation; Drug discontinuation; Patient-reported outcomes; Patient satisfaction endpoints; Rivaroxaban; Warfarin

\section{INTRODUCTION}

Patient-reported outcomes (PROs) used in clinical practice and clinical research are health outcomes reported directly by the patient,

$\overline{\text { C. C. Nessel }}$

Janssen Research and Development, Raritan, NJ, USA

D. E. Singer

Massachusetts General Hospital and Harvard

Medical School, Boston, MA, USA

M. R. Patel · J. P. Piccini

Duke University Health System, Durham, NC, USA without interpretation or confirmation from an intermediary, such as a physician, nurse, or study coordinator [1]. In 2004, the National Institutes of Health roadmap for clinical research identified the development of PROs as a key priority, and multiple PRO tools have been created and validated [2-14]. Guidelines have been published recommending best practices for PRO use [15], and there have been calls to comprehensively integrate PROs into cardiovascular clinical trials [16]. PROs have been used to compare patient satisfaction with warfarin versus the direct oral anticoagulants (DOACs), and have found higher satisfaction with DOACs in patients with pulmonary embolism (PE) [17], deep venous thrombosis (DVT) [18], and atrial fibrillation (AF) [19-21]. However, these studies did not examine whether increased satisfaction predicts better medication adherence. Nonadherence precludes treatment efficacy and leads to worse outcomes [22], and in clinical trials, study drug discontinuation can undermine the scientific rigor of the study. The objective of this substudy from The Rivaroxaban Once Daily Oral Direct Factor $\mathrm{Xa}$ Inhibition Compared with Vitamin K Antagonism for Prevention of Stroke and Embolism Trial in Atrial Fibrillation (ROCKET $\mathrm{AF}$ ) [23] was to determine if PROs assessing study drug satisfaction are associated with study drug discontinuation. We hypothesized that patients who were more satisfied with the study drug would be less likely to discontinue the study drug.

\section{METHODS}

The design of ROCKET AF (NCT00403767) has been previously described [23]. In brief, ROCKET AF was a phase III, randomized, double-blind, placebo-controlled, multicenter trial of rivaroxaban compared with dose-adjusted warfarin for the prevention of stroke and systemic embolism in patients with nonvalvular AF. A total of 14,264 patients were randomized at 1178 centers in 45 countries. The protocol was approved by ethics committees at participating sites, and all patients provided written informed consent. Patients were included if 
they had moderate-to-high risk for stroke. Patients were randomized to rivaroxaban $20 \mathrm{mg}$ once daily, or $15 \mathrm{mg}$ once daily in patients with a creatinine clearance of $30-49 \mathrm{~mL} / \mathrm{min}$, or dose-adjusted warfarin with a target international normalized ratio of 2.0-3.0. It was intended that patients would continue the therapy throughout the duration of the trial, unless discontinuation was clinically indicated, or after meeting a primary endpoint in which case discontinuation was mandated.

A subset of patients in ROCKET AF was given two treatment satisfaction questionnaires: The Anti-Clot Treatment Scale (ACTS) and the Treatment Satisfaction Questionnaire for Medication version II (TSQM II). Both scales are validated [24-27] and have been used extensively in previous trials of anticoagulants [17-21, 28]. The subset of patients given the questionnaires was selected at random from pre-selected sites in the USA, Germany, and The Netherlands. Sample size calculation was not performed, as these analyses examining PROs and study-drug discontinuation were not preplanned at the start of ROCKET AF.

The ACTS is a 15-item patient-reported instrument of satisfaction with anticoagulant treatment and is summarized as two scales that represent both negative and positive aspects of anticoagulation treatment: ACTS Burdens (12 items), and ACTS Benefits (3 items). The ACTS is an adaptation of the previously validated Duke Anticoagulation Satisfaction Score [29]. For each item, patient experience with anticoagulation treatment is rated on a five-point Likert scale from "Not at all" to "Extremely." The 12 items of ACTS Burdens are reverse coded (scored 5-1), whereas the three items of ACTS Benefits are coded normally (scored 1-5), so that higher scores indicate greater patient satisfaction. Item scores are summed across domains to give an ACTS Burdens score ranging from 12 to 60 and an ACTS Benefits score ranging from 3 to 15. A patient must have data for all items of a scale for the scale to be calculated. The ACTS was measured at $4,8,12$, and 24 weeks after randomization.

The TSQM II consists of ten items representing four scales: Effectiveness (2 items), Side Effects (3 items), Convenience (3 items), and
Global Satisfaction (2 items). Experiences of treatment satisfaction are rated on five-point and seven-point Likert scales from "Extremely dissatisfied" to "Extremely satisfied," with scale scores being converted to a score between 0 and 100 , where higher scores indicate greater satisfaction with treatment. A patient must have data for all items of a scale in order for the scale to be calculated, except for the Side Effects and Convenience scales, for which up to one item each could be missing. The TSQM II was measured at 4 and 24 weeks after randomization.

The current analysis includes data from both questionnaires at 4 and 24 weeks, the time points at which both surveys were carried out. Our primary analysis examines survey responses at 4 weeks, a time point that is far enough into the course of therapy to gauge satisfaction, but potentially early enough to intervene before discontinuation occurs. In addition, we examined longer-term satisfaction using data at 24 weeks. Patients who were randomized and received at least one dose of study drug were included in the analysis if they had complete data for both ACTS and TSQM II at 4 weeks and were still on the assigned study drug at the 4-week visit.

Details about study drug administration were collected rigorously including timing, duration, and reason for interruptions or discontinuation of study drug. Study drug discontinuation was defined as a permanent discontinuation of randomized study drug (i.e., stopping study drug and not starting it again later). Temporary interruptions of study drug, defined as stopping study drug and starting it again later (for example for a surgical procedure), were not included as discontinuation outcomes. These discontinuation definitions were used across all ROCKET AF analyses that considered discontinuation in any way [30]. Discontinuations were classified as patient-driven discontinuation or non-patientdriven discontinuation. Patient-driven discontinuation was defined as stopping study drug due to any of the following reasons: withdrawal of consent, noncompliance, or loss to follow-up. Non-patient-driven discontinuation was defined as discontinuation for any other reason (e.g., adverse event, clinical efficacy endpoint reached, investigator decision, protocol violation). 
Baseline characteristics and reasons for discontinuation are summarized using number (percent) for categorical variables and median (25th, 75th percentiles) for continuous variables. Scores for individual scales are summarized using both median (25th, 75th percentiles) and mean (standard deviation). These scale summaries were carried out for both 4-week and 24-week data.

Patients were categorized as satisfied or not satisfied in two ways, using 4-week data. For our primary analysis, for each scale, we found the minimum score reflecting satisfaction (e.g., an answer of Satisfied, Very Satisfied, or Extremely Satisfied for all score components; details in the Supplemental Appendix). A patient was then considered satisfied at 4 weeks if their score was equal to or greater than this minimum score (see Supplemental Appendix: Definition of "satisfied vs. "not satisfied" for each scale; minimum score for satisfaction for each subscale was: ACTS Benefits $>12$, ACTS Burdens $>42$, TSQM Effectiveness $>66.67$, Side Effects $>100$, TSQM Convenience $>66.7$, TSQM Global Satisfaction $>66.7$ ). For our sensitivity analysis, to address any possible subjectivity in our definition for the primary analysis, we used the median of each score distribution as the minimum score cut-off to define satisfaction.

Rates of patient-driven discontinuation after the 4-week survey are summarized for satisfaction groups using events per 100 patient-years and total events. To formally test this relationship, we used Fine and Gray models, which are semi-parametric proportional hazards models that account for competing risks, in this case, non-patient-driven discontinuation. Start time for the models was the time of the 4-week questionnaire. Models were adjusted for the following variables found to be predictive of patient-driven discontinuation in the full ROCKET AF cohort (details of model development are in the Supplemental Appendix): age, sex, race, geographic region, prior stroke or transient ischemic attack, history of depression, prior vitamin $\mathrm{K}$ antagonist (VKA) use, and postrandomization occurrence of bleeding or a temporary interruption of study drug for a procedure. Risk relationships are presented as hazard ratios with 95\% confidence intervals.
All analyses were conducted using SAS version 9.4 or higher (SAS Institute Inc., Cary, NC).

\section{RESULTS}

Of 14,264 patients in ROCKET AF, 1577 participated in the Patient Satisfaction substudy and 1181 remained on study drug at 4 weeks and completed both the ACTS and TSQM II questionnaires 4 weeks after starting the study drug. Of these patients, $572(48.4 \%)$ had been randomized to rivaroxaban, $609(52.6 \%)$ to warfarin. Baseline demographic characteristics were similar in the two groups (Table 1). A total of 855 patients completed both the ACTS and TSQM II at 24 weeks ( $72 \%$ of those who completed both questionnaires at 4 weeks), including 398 (46.5\% of those who completed both questionnaires at 24 weeks) randomized to rivaroxaban, and $457(53.4 \%$ of those who completed both questionnaires at 24 weeks) randomized to warfarin.

Patient satisfaction measures at 4 weeks after randomization, overall and by randomized treatment, are presented in Table 2 and Fig. 1. As expected, because of the double-blind design, no differences were observed between the randomized treatment arms in any scales.

In the longer term, satisfaction scores at 24 weeks were similar to those at 4 weeks (Supplemental Table 1 and Supplemental Figure 1), indicating that levels of satisfaction remained consistent over time.

Over a median follow-up of 1.6 years, 448 early permanent study drug discontinuations occurred; 116 (26\%) of those were patient-driven (Table 3). Of those, 100 were due to withdrawal of consent and 16 to noncompliance. Among the 332 non-patient-driven discontinuations, 210 were due to adverse events, 52 to reaching a clinical efficacy endpoint, 44 to investigator decision, and 26 to protocol violations. Discontinuation reasons for the entire ROCKET AF cohort are in Supplemental Table 2.

The relationship between satisfaction and discontinuation is presented in Table 4 and Fig. 2. Although on three of the subscales (ACTS Burdens, ACTS Benefits, and TSQM II Effectiveness) there were numerically higher rates of 
Table 1 Baseline characteristics for patients participating in the patient satisfaction surveys

\begin{tabular}{|c|c|c|c|}
\hline Variable & All patients $(N=1181)$ & Rivaroxaban $(N=572)$ & Warfarin $(N=609)$ \\
\hline Randomized to rivaroxaban & $572(48 \%)$ & & \\
\hline Age (years) & $75(67,79)$ & $75(67,79)$ & $75(67,79)$ \\
\hline Female sex & $398(34 \%)$ & $189(33 \%)$ & $209(34 \%)$ \\
\hline \multicolumn{4}{|l|}{ Geographic region } \\
\hline North America & $776(66 \%)$ & $373(65 \%)$ & $403(66 \%)$ \\
\hline Western Europe & $405(34 \%)$ & $199(35 \%)$ & $206(34 \%)$ \\
\hline \multicolumn{4}{|l|}{ Type of AF } \\
\hline Persistent & $881(75 \%)$ & $423(74 \%)$ & $458(75 \%)$ \\
\hline Paroxysmal & $286(24 \%)$ & $139(24 \%)$ & $147(24 \%)$ \\
\hline New onset & $14(1 \%)$ & $10(2 \%)$ & $4(1 \%)$ \\
\hline $\mathrm{CHADS}_{2}$ score, mean $(\mathrm{SD})$ & $3.2(1.0)$ & $3.2(1.0)$ & $3.2(1.0)$ \\
\hline \multicolumn{4}{|l|}{$\mathrm{CHADS}_{2}$ score } \\
\hline 2 & $316(27 \%)$ & $146(26 \%)$ & $170(28 \%)$ \\
\hline 3 & $471(40 \%)$ & $228(40 \%)$ & $243(40 \%)$ \\
\hline 4 & $270(23 \%)$ & $137(24 \%)$ & $133(22 \%)$ \\
\hline 5 & $96(8 \%)$ & $47(8 \%)$ & $49(8 \%)$ \\
\hline 6 & $28(2 \%)$ & $14(2 \%)$ & $14(2 \%)$ \\
\hline \multicolumn{4}{|l|}{ Presenting characteristics } \\
\hline BMI $\left(\mathrm{kg} / \mathrm{m}^{2}\right)$ & $29.8(26.3,33.8)$ & $29.9(26.6,34.3)$ & $29.8(26.0,33.5)$ \\
\hline $\mathrm{SBP}(\mathrm{mmHg})$ & $130(120,140)$ & $130(120,140)$ & $130(120,142)$ \\
\hline $\mathrm{DBP}(\mathrm{mmHg})$ & $78(70,85)$ & $78(70,85)$ & $78(70,85)$ \\
\hline Heart rate $(\mathrm{bpm})$ & $72(63,82)$ & $72(63,81)$ & $72(63,82)$ \\
\hline Creatinine clearance $^{\mathrm{a}}(\mathrm{mL} / \mathrm{min})$ & $70(54,93)$ & $72(55,94)$ & $69(53,93)$ \\
\hline \multicolumn{4}{|l|}{ Baseline comorbidities } \\
\hline Prior stroke/TIA/embolism & $464(39 \%)$ & $225(39 \%)$ & $239(39 \%)$ \\
\hline Congestive HF & $585(50 \%)$ & $286(50 \%)$ & $299(49 \%)$ \\
\hline Prior MI & $248(21 \%)$ & $122(21 \%)$ & $126(21 \%)$ \\
\hline PAD & $84(7 \%)$ & $34(6 \%)$ & $50(8 \%)$ \\
\hline Hypertension & $1092(92 \%)$ & $531(93 \%)$ & $561(92 \%)$ \\
\hline Diabetes & $540(46 \%)$ & $263(46 \%)$ & $277(45 \%)$ \\
\hline COPD & $181(15 \%)$ & $94(16 \%)$ & $87(14 \%)$ \\
\hline
\end{tabular}


Table 1 continued

\begin{tabular}{llll}
\hline Variable & All patients $(\boldsymbol{N = 1 1 8 1})$ & Rivaroxaban $(\boldsymbol{N}=\mathbf{5 7 2})$ & Warfarin $(\boldsymbol{N}=\mathbf{6 0 9})$ \\
\hline Medications & & & \\
Prior VKA use & $1020(86 \%)$ & $489(85 \%)$ & $531(87 \%)$ \\
Prior chronic aspirin use & $324(27 \%)$ & $158(28 \%)$ & $166(27 \%)$ \\
ACE inhibitor/ARB at baseline & $894(76 \%)$ & $444(78 \%)$ & $450(74 \%)$ \\
Beta blocker at baseline & $866(73 \%)$ & $410(72 \%)$ & $456(75 \%)$ \\
Digitalis at baseline & $443(38 \%)$ & $207(36 \%)$ & $236(39 \%)$ \\
Diuretic at baseline & $749(63 \%)$ & $366(64 \%)$ & $383(63 \%)$ \\
\hline
\end{tabular}

Continuous variables are shown as median (25th, 75th percentiles) except where noted, and categorical variables as no. (\%) $A C E$ angiotensin converting enzyme, $A F$ atrial fibrillation, $A R B$ angiotensin receptor blocker, $B M I$ body mass index, $b p m$ beats per minute, $C H A D S_{2}$ congestive heart failure, hypertension, age $\geq 75$ years, diabetes mellitus, prior stroke or transient ischemic attack or thromboembolism, COPD chronic obstructive pulmonary disease, DBP diastolic blood pressure, $H F$ heart failure, $M I$ myocardial infarction, $P A D$ peripheral artery disease, $S B P$ systolic blood pressure, $S D$ standard deviation, $T I A$ transient ischemic attack, $V K A$ vitamin $\mathrm{K}$ antagonist

a Calculated using the Cockcroft-Gault equation

Table 2 ACTS and TSQM scores at 4 weeks after randomization, overall and by randomized treatment

\begin{tabular}{|c|c|c|c|c|}
\hline Questionnaire/Scale & All patients $(N=1181)$ & Rivaroxaban $(N=572)$ & Warfarin $(N=609)$ & $P$ value \\
\hline \multicolumn{5}{|l|}{ ACTS } \\
\hline \multirow[t]{2}{*}{ ACTS Burdens } & $57(54,59)$ & $57(54,59)$ & $57(53,59)$ & 0.20 \\
\hline & $55.6(5.0)$ & $55.9(4.7)$ & $55.4(5.2)$ & \\
\hline \multirow[t]{2}{*}{ ACTS Benefits } & $12(10,14)$ & $12(10,14)$ & $12(9,14)$ & 0.54 \\
\hline & $11.3(3.1)$ & $11.4(3.0)$ & $11.3(3.2)$ & \\
\hline \multicolumn{5}{|l|}{ TSQM II } \\
\hline \multirow[t]{2}{*}{ Effectiveness } & $67(67,83)$ & $67(67,83)$ & $67(67,83)$ & 0.68 \\
\hline & $71.9(19.1)$ & $72.1(19.1)$ & $71.6(19.1)$ & \\
\hline \multirow[t]{2}{*}{ Side Effects } & $100(92,100)$ & $100(92,100)$ & $100(92,100)$ & 0.48 \\
\hline & $93.2(14.9)$ & $92.8(15.9)$ & $93.6(13.9)$ & \\
\hline \multirow[t]{2}{*}{ Convenience } & $78(67,89)$ & $78(67,89)$ & $78(67,83)$ & 0.26 \\
\hline & $77.2(14.8)$ & $77.7(15.3)$ & $76.8(14.4)$ & \\
\hline \multirow[t]{2}{*}{ Global Satisfaction } & $75(67,83)$ & $75(67,83)$ & $75(67,83)$ & 0.24 \\
\hline & $75.4(16.1)$ & $75.9(16.4)$ & $74.9(15.9)$ & \\
\hline
\end{tabular}

For each scale, the top entry is median (25th, 75th percentiles) score and the bottom entry is mean (SD)

ACTS Anti-Clot Treatment Scale, TSQM II Treatment Satisfaction Questionnaire for Medication version II 


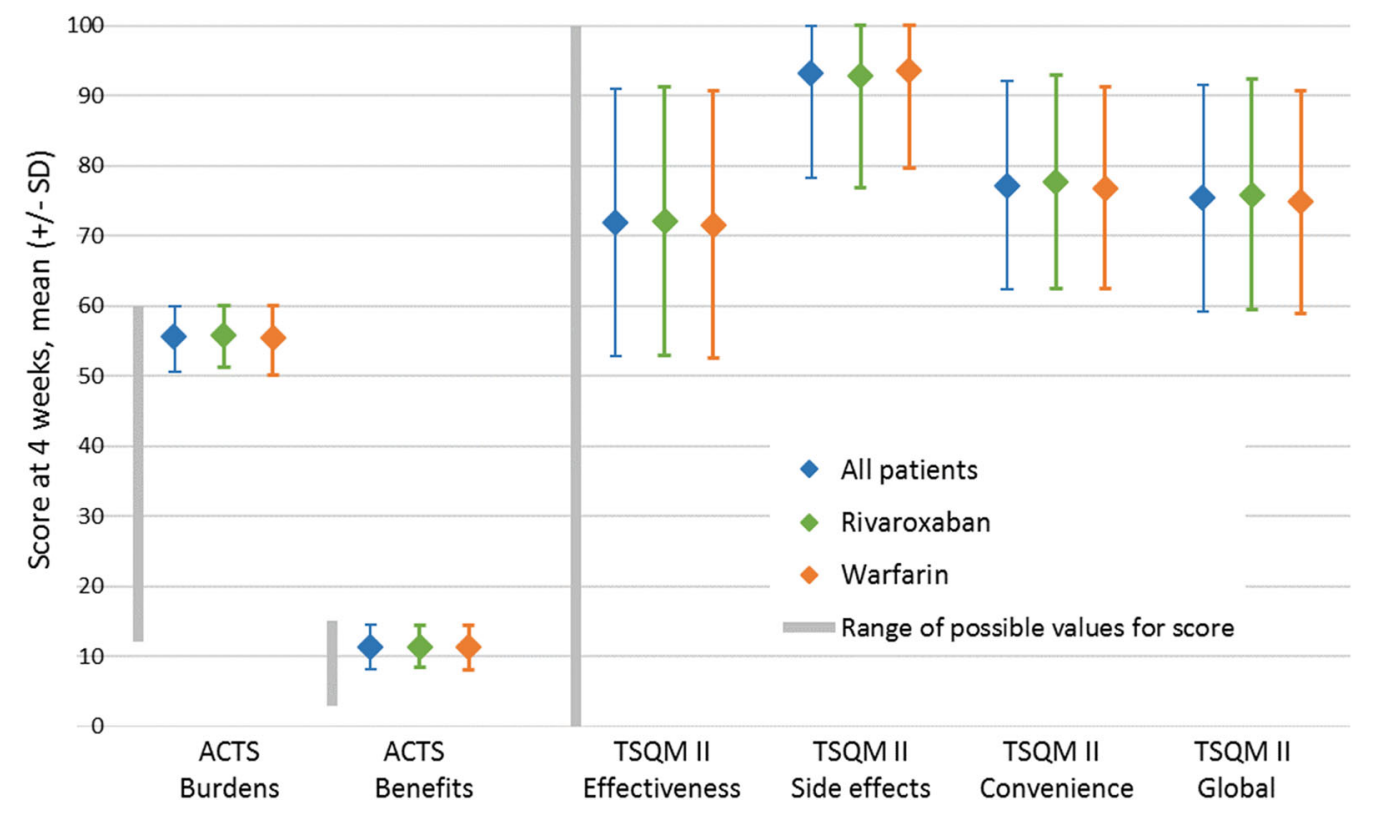

Fig. 1 Scales of patient satisfaction for the entire analysis cohort and by randomized treatment at 4 weeks after randomization

Table 3 Reasons for early permanent study drug discontinuation in the analysis cohort

\begin{tabular}{llll}
\hline & All patients $(\boldsymbol{N}=\mathbf{1 1 8 1})$ & Rivaroxaban $(\boldsymbol{N}=\mathbf{5 7 2})$ & Warfarin $(\boldsymbol{N}=\mathbf{6 0 9})$ \\
\hline Discontinued study drug early & $448(37.9 \%)$ & $213(37.2 \%)$ & $235(38.6 \%)$ \\
Reason for discontinuation (\% among discontinuing patients) & & \\
Patient-driven discontinuation & $116(25.9 \%)$ & $52(24.4 \%)$ & $64(27.2 \%)$ \\
Consent withdrawn & $100(22.3 \%)$ & $46(21.6 \%)$ & $54(23.0 \%)$ \\
Noncompliant with study medication & $16(3.6 \%)$ & $6(2.8 \%)$ & $10(4.3 \%)$ \\
Lost to follow-up & 0 & 0 & 0 \\
Non-patient-driven discontinuation & $332(74.1 \%)$ & $161(75.6 \%)$ & $171(72.8 \%)$ \\
Adverse event & $210(46.9 \%)$ & $109(51.2 \%)$ & $101(43.0 \%)$ \\
Clinical efficacy endpoint reached & $52(11.6 \%)$ & $24(11.3 \%)$ & $28(11.9 \%)$ \\
Investigator decision & $44(9.8 \%)$ & $19(8.9 \%)$ & $25(10.6 \%)$ \\
Protocol violation & $26(5.8 \%)$ & $9(4.2 \%)$ & $17(7.2 \%)$ \\
\hline
\end{tabular}

Data presented as no. (\%)

discontinuations in the less satisfied group, there were no statistically significant differences in discontinuation rates between the more and the less satisfied groups for any of the six satisfaction subscales. The results of our sensitivity analysis (which compared patients who were above versus below median satisfaction) are displayed in Supplemental Table 3. In this analysis, too, there were no statistically 
Table 4 Association of patient satisfaction scales at 4 weeks with subsequent early study drug discontinuation

\begin{tabular}{|c|c|c|c|c|c|}
\hline Questionnaire/Scale & Cut-off ${ }^{n}$ & Not satisfied ${ }^{\mathbf{b}}$ & Satisfied $^{\mathbf{b}}$ & $\begin{array}{l}\text { HR }(95 \% \text { CI })^{c} \text { Not } \\
\text { satisfied vs. satisfied }\end{array}$ & $P$ value ${ }^{c}$ \\
\hline \multicolumn{6}{|l|}{ ACTS } \\
\hline \multicolumn{6}{|l|}{ Burdens } \\
\hline$N$ & 42 & 29 & 1152 & & \\
\hline Events/100 pt-years (total events) & & $6.89(4)$ & $5.41(112)$ & $1.44(0.44-3.46)$ & 0.50 \\
\hline \multicolumn{6}{|l|}{ Benefits } \\
\hline$N$ & 12 & 462 & 719 & & \\
\hline Events/100 pt-years (total events) & & $6.02(51)$ & $5.07(65)$ & $1.18(0.81-1.71)$ & 0.38 \\
\hline \multicolumn{6}{|l|}{ TSQM II } \\
\hline \multicolumn{6}{|l|}{ Effectiveness } \\
\hline$N$ & 67 & 195 & 986 & & \\
\hline Events/100 pt-years (total events) & & $7.00(23)$ & $5.16(93)$ & $1.23(0.76-1.91)$ & 0.38 \\
\hline \multicolumn{6}{|l|}{ Side Effects } \\
\hline$N$ & 100 & 326 & 855 & & \\
\hline Events $/ 100$ pt-years (total events) & & $5.55(31)$ & $5.41(85)$ & $0.99(0.64-1.48)$ & 0.95 \\
\hline \multicolumn{6}{|l|}{ Convenience } \\
\hline$N$ & 67 & 98 & 1083 & & \\
\hline Events/100 pt-years (total events) & & $4.61(8)$ & $5.52(108)$ & $0.77(0.34-1.48)$ & 0.48 \\
\hline \multicolumn{6}{|l|}{ Global Satisfaction } \\
\hline$N$ & 67 & 149 & 1032 & & \\
\hline Events/100 pt-years (total events) & & $5.32(14)$ & $5.47(102)$ & $0.95(0.52-1.61)$ & 0.86 \\
\hline
\end{tabular}

ACTS Anti-Clot Treatment Scale, CI confidence interval, HR hazard ratio, TSQM II Treatment Satisfaction Questionnaire for Medication version II

${ }^{a}$ Satisfaction is defined as a score at or above the cut-off

b Groups are defined using "satisfied" or "not satisfied" survey answers (primary analysis; see Methods)

${ }^{c}$ Hazard ratio and $P$ value for discontinuation are from adjusted model

significant differences in discontinuation rates between more and less satisfied patients.

\section{DISCUSSION}

In this substudy of anticoagulation-related quality of life from the ROCKET AF trial, patients with AF who were randomly assigned in a double-blind fashion to rivaroxaban or warfarin reported no difference in satisfaction with study drug at 4 versus 24 weeks after enrollment. As expected given the double-blind trial design, similar satisfaction between patients randomized to rivaroxaban versus warfarin was observed. However, in contrast to our hypothesis, we found no association between anticoagulation satisfaction and patient-driven study drug discontinuation. 


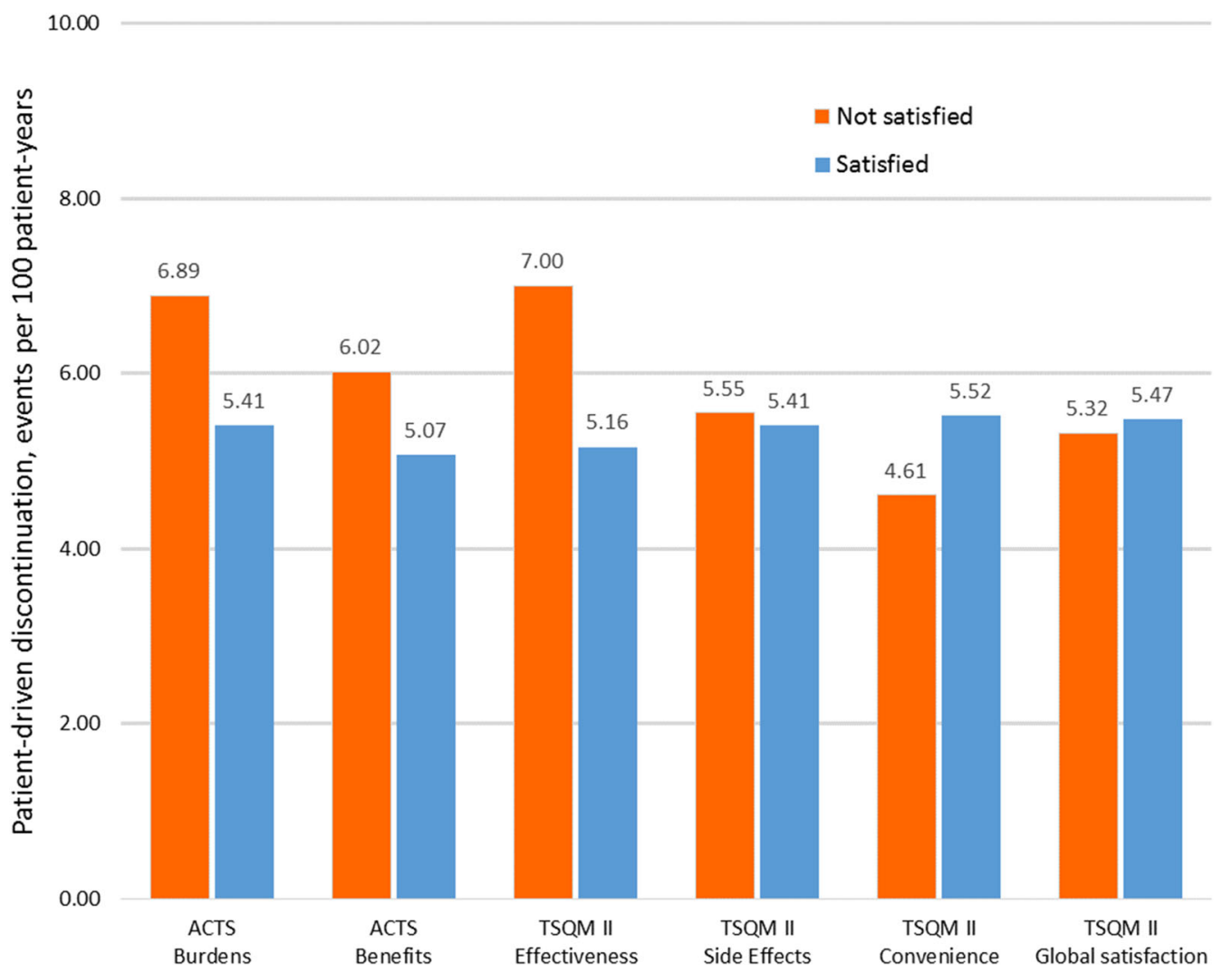

Fig. 2 Patient-driven discontinuation rate (events/100 patient-years) by satisfaction levels at 4 weeks (primary analysis)

As patient-centered care assumes a more prominent role in treatment guidelines, the need to systematically integrate PROs in cardiovascular research has been emphasized $[2,15,16]$. These results build on previous studies of patient satisfaction with anticoagulation. Earlier work has shown that some patients have lower perceived quality of life with warfarin [31, 32], validated PROs measuring satisfaction with warfarin and the DOACs [24-27], and suggested that patients have higher satisfaction with rivaroxaban versus warfarin across a number of indications [17-21]. Furthermore, studies have demonstrated low rates of drug adherence, both in clinical trials and in practice [33-38]. This study builds on these two lines of research by examining whether PROs measuring satisfaction predict anticoagulant nonadherence.

Although we did not find any significant relationship between study drug satisfaction and discontinuation, we did observe some nonsignificant associations. Higher satisfaction on ACTS Burdens, ACTS Benefits, and TSQM II Effectiveness were all nonsignificantly associated with lower discontinuation. This association for the TSQM II Effectiveness subscale was the largest and was present in both our primary and secondary analyses. This may suggest that patients would be willing to tolerate side effects and inconvenience as long as they believe that a drug is effective. Alternatively, it is possible that these previously validated anticoagulation satisfaction scales may not be as powerful predictors in $\mathrm{AF}$ as they are in thromboembolic disease. This observation may generate the hypothesis that patients who have already had DVT report higher satisfaction with anticoagulants, and more generally that efficacy is perceived as higher when a drug is used for secondary versus primary prevention. Further studies exploring this hypothesis and the impact of PROs and drug discontinuation 
should be studied in open-label trials with larger sample sizes.

Participants assigned to rivaroxaban and warfarin had similar satisfaction at 4 weeks and 24 weeks in this analysis likely because of the double-blind study design that included sophisticated sham INR testing in the rivaroxaban group. These results support that the blinding of the participants was preserved with this approach [23]. Other studies of comparative satisfaction used conditions more similar to actual use, involving blood draws with warfarin but not with rivaroxaban $[17,18]$. The similar satisfaction with warfarin and rivaroxaban on every satisfaction subscale suggests that the difference in satisfaction seen in other studies may be attributable to the increased monitoring with warfarin, rather than differences in drug side effects or other non-monitoring-related drug effects.

This study has several limitations. First, only a subset of trial participants from North America and Western Europe participated in the substudy, limiting the generalizability and statistical power. Second, there were a relatively small number of discontinuation events, further reducing statistical power. Third, given the small sample and few endpoint events it was not possible to evaluate the relationships between satisfaction, adherence, and other clinical outcomes.

\section{CONCLUSIONS}

In conclusion, in this substudy from ROCKET AF, no statistically significant association between self-reported study drug satisfaction and patientdriven study drug discontinuation was observed. As expected in a double-blind trial, no significant difference between satisfaction between the rivaroxaban group and the warfarin group was observed. Although these results were negative, the importance of PRO data, even in the context of blinded randomized controlled trials, will undoubtedly continue to increase. ROCKET AF successfully collected PRO data in a large clinical trial, and these results may provide important lessons for future clinical trials that collect and monitor PROs to ascertain satisfaction, and explore the relation of PROs to adherence and other clinical outcomes.

\section{ACKNOWLEDGMENTS}

Funding. The ROCKET AF trial was funded by Johnson \& Johnson and Bayer. No funding or sponsorship was received for this study or publication of this article.

Medical Writing Assistance. We appreciate the editorial assistance that was provided by Elizabeth Cook, at the Duke Clinical Research Institute.

Authorship. All named authors meet the International Committee of Medical Journal Editors (ICMJE) criteria for authorship for this article, take responsibility for the integrity of the work as a whole, and have given their approval for this version to be published.

Disclosures. Leo Ungar and Anne Hellkamp have nothing to disclose. Fatima Rodriguez: Research funding from Verily Life Sciences; advisor to HealthPals; is a member of the journal's Editorial Board. Richard Becker: Consulting fees/Honoraria from Boehringer Ingelheim, Daiichi-Sankyo, Portola; Research grant from AstraZeneca. Scott Berkowitz: Employee of Bayer US LLC. Guenter Breithardt: Consulting fees/Honoraria from Bayer HealthCare, Johnson \& Johnson, Sanofi-Aventis. Keith Fox: Consulting fees/Honoraria from AstraZeneca, Bayer, Janssen, Merck \& Co., Sanofi-Aventis, Regeneron; Research grants from Eli Lilly, GlaxoSmithKline. Werner Hacke: Consulting fees/Honoraria from Bayer. Jonathan Halperin: Consulting fees/Honoraria from Bayer HealthCare, Boehringer Ingelheim, Medtronic Inc., Ortho-McNeil-Janssen, Pfizer. Graeme Hankey: Speaker's bureau: Bayer. Christopher Nessel: Employee of Janssen Research \& Development. Daniel Singer: Consulting fees/Honoraria from Boehringer Ingelheim, Bristol-Myers Squibb, CVS Health, Johnson \& Johnson, Medtronic, Merck, Pfizer; Research grants from Boehringer Ingelheim, Bristol-Myers Squibb, Medtronic. 
Manesh Patel: Consulting fees/Honoraria from AstraZeneca, Bayer, Janssen; Research grants from AstraZeneca, Bayer, HeartFlow, Janssen, Medtronic, NHLBI. Jonathan Piccini: Research grants from Abbott Medical, ARCA biopharma, Boston Scientific, Gilead, Janssen Pharmaceuticals, NHLBI, and Verily; Consulting fees/Honoraria from Allergan, Bayer, Johnson \& Johnson, Medtronic, Sanofi, Phillips. Kenneth Mahaffey: Consulting fees/Honoraria from Eli Lilly, ACC, AstraZeneca, BAROnova, Bayer, Bio2 Medical, Boehringer Ingelheim, Bristol-Myers Squibb, Cubist, Elsevier, Epson, Forest, GlaxoSmithKline, Johnson \& Johnson, Medtronic, Merck, Mt. Sinai, MyoKardia, Omthera, Portola, Purdue Pharma, Springer Publishing, The Medicines Company, Vindico, WebMD; Ownership interest in BioPrint Fitness; Research grants from Amgen, Boehringer Ingelheim, Daiichi Sankyo, Johnson \& Johnson, Medtronic, St. Jude, Tenax; is a member of the journal's Editorial Board.

Compliance with Ethics Guidelines. The protocol was approved by ethics committees at participating sites, and all patients provided written informed consent.

Data Availability. The data sets generated during and/or analyzed during the current study are not publically available. Please contact the corresponding author for further inquiries.

Open Access. This article is distributed under the terms of the Creative Commons Attribution-NonCommercial 4.0 International License (http://creativecommons.org/licenses/ by-nc/4.0/), which permits any noncommercial use, distribution, and reproduction in any medium, provided you give appropriate credit to the original author(s) and the source, provide a link to the Creative Commons license, and indicate if changes were made.

\section{REFERENCES}

1. Deshpande PR, Rajan S, Sudeepthi BL, Abdul Nazir CP. Patient-reported outcomes: a new era in clinical research. Perspect Clin Res. 2011;2:137-44.
2. Carle AC, Cella D, Cai L, Choi SW, Crane PK, Curtis SM, Gruhl J, Lai JS, Mukherjee S, Reise SP, Teresi JA, Thissen D, Wu EJ, Hays RD. Advancing promis's methodology: results of the third patient-reported outcomes measurement information system (PROMIS $\left.\left({ }^{\circledR}\right)\right)$ Psychometric Summit. Expert Rev Pharm Out. 2011;11:677-84.

3. Alonso J, Bartlett SJ, Rose M, Aaronson NK, Chaplin JE, Efficace F, Leplège A, Lu A, Tulsky DS, Raat H, Ravens-Sieberer U, Revicki D, Terwee CB, Valderas JM, Cella D, Forrest CB. The case for an international patient-reported outcomes measurement information system $\left(\right.$ PROMIS $\left.^{\circledR}\right)$ initiative. Health Qual Life Outcomes. 2013;11:210.

4. Cella D, Riley W, Stone A, Rothrock N, Reeve B, Yount S, Amtmann D, Bode R, Buysse D, Choi S, Cook K, Devellis R, DeWalt D, Fries JF, Gershon R, Hahn EA, Lai JS, Pilkonis P, Revicki D, Rose M, Weinfurt K, Hays R. The Patient-Reported Outcomes Measurement Information System (PROMIS) developed and tested its first wave of adult self-reported health outcome item banks: 2005-2008. J Clin Epidemiol. 2010;63:1179-94.

5. Cella D, Yount S, Rothrock N, Gershon R, Cook K, Reeve B, Ader D, Fries JF, Bruce B, Rose M. The Patient-Reported Outcomes Measurement Information System (PROMIS) progress of an NIH roadmap cooperative group during its first two years. Med Care. 2007;45:S3-11.

6. Hahn EA, DeVellis RF, Bode RK, Garcia SF, Castel LD, Eisen SV, Bosworth HB, Heinemann AW, Rothrock N, Cella D. Measuring social health in the Patient-Reported Outcomes Measurement Information System (PROMIS): item bank development and testing. Qual Life Res. 2010;19:1035-44.

7. Hays RD, Bjorner JB, Revicki DA, Spritzer KL, Cella D. Development of physical and mental health summary scores from the Patient-Reported Outcomes Measurement Information System (PROMIS) global items. Qual Life Res. 2009;18:873-80.

8. Lai JS, Garcia S, Cella D. The Patient-Reported Outcomes Measurement Information System cancer pain item bank (PROMIS-CA PAIN). Value Health. 2008;11:A486.

9. Lai JS, Garcia SF, Cella D. The NIH Patient-Reported Outcomes Measurement Information System cancer fatigue item bank (PROMIS CA-FIB): validation with cancer population. Qual Life Res. 2010;19:99.

10. Pilkonis PA, Choi SW, Reise SP, Stover AM, Riley WT, Cella D. Item banks for measuring emotional distress from the Patient-Reported Outcomes Measurement Information System $\left(\right.$ PROMIS $\left.^{\circledR}\right)$ : depression, anxiety, and anger. Assessment. 2011;18:263-83. 
11. Reeve BB, Hays RD, Bjorner JB, Ook KF, Crane PK, Teresi JA, Thissen D, Revicki DA, Weiss DJ, Hambleton RK, Liu H, Gershon R, Reise SP, Lai JS, Cella D. Psychometric evaluation and calibration of health-related quality of life item banks-plans for the Patient-Reported Outcomes Measurement Information System (PROMIS). Med Care. 2007;45:S22-31.

12. Riley WT, Pilkonis P, Cella D. Application of the national institutes of health Patient-Reported Outcome Measurement Information System (PROMIS) to mental health research. J Ment Health Policy. 2011;14:201-8.

13. Rothrock NE, Hays RD, Spritzer K, Yount SE, Riley $\mathrm{W}$, Cella D. Relative to the general us population, chronic diseases are associated with poorer healthrelated quality of life as measured by the PatientReported Outcomes Measurement Information System (PROMIS). J Clin Epidemiol. 2010;63: 1195-204.

14. Haverman L, Grootenhuis MA, Raat H, Rossum MA, van Dulmen-den Broeder E, Hoppenbrouwers K, Correia H, Cella D, Roorda LD, Terwee CB. DutchFlemish translation of nine pediatric item banks from the Patient-Reported Outcomes Measurement Information System (PROMIS ${ }^{\circledR}$ ). Qual Life Res. 2016;25:761-5.

15. Calvert M, Kyte D, Mercieca-Bebber R, Slade A, Chan AW, King MT. Guidelines for inclusion of patient-reported outcomes in clinical trial protocols: the SPIRIT-PRO extension. JAMA. 2018;319: 483-94.

16. Anker SD, Agewall S, Borggrefe M, Calvert M, Jaime Caro J, Cowie MR, Ford I, Paty JA, Riley JP, Swedberg K, Tavazzi L, Wiklund I, Kirchhof P. The importance of patient-reported outcomes: a call for their comprehensive integration in cardiovascular clinical trials. Eur Heart J. 2014;35:2001-9.

17. Prins $\mathrm{MH}$, Bamber L, Cano SJ, Wang MY, Erkens P, Bauersachs R, Lensing AW. Patient-reported treatment satisfaction with oral rivaroxaban versus standard therapy in the treatment of pulmonary embolism; results from the EINSTEIN PR trial. Thromb Res. 2015;135:281-8.

18. Bamber L, Wang MY, Prins MH, Ciniglio C, Bauersachs R, Lensing AW, Cano SJ. Patient-reported treatment satisfaction with oral rivaroxaban versus standard therapy in the treatment of acute symptomatic deep-vein thrombosis. Thromb Haemost. 2013;110:732-41.

19. Fumagalli S, Cardini F, Roberts AT, Boni S, Gabbai D, Calvani S, Casalone Rinaldi M, Manetti S, Tarantini F, Marchionni N. Psychological effects of treatment with new oral anticoagulants in elderly patients with atrial fibrillation: a preliminary report. Aging Clin Exp Res. 2015;27:99-102.

20. Hohnloser SH, Cappato R, Ezekowitz MD, Evers T, Sahin K, Kirchhof P, Meng IL, van Eickels M, Camm AJ. Patient-reported treatment satisfaction and budget impact with rivaroxaban vs. Standard therapy in elective cardioversion of atrial fibrillation: a post hoc analysis of the X-VeRT trial. Europace. 2016;18:184-90.

21. Coleman CI, Haas S, Turpie AG, Kuhls S, Hess S, Evers T, Amarenco P, Kirchhof P, Camm AJ. Impact of switching from a vitamin $\mathrm{k}$ antagonist to rivaroxaban on satisfaction with anticoagulation therapy: the XANTUS-ACTS substudy. Clin Cardiol. 2016;39:565-9.

22. Simpson SH, Eurich DT, Majumdar SR, Padwal RS, Tsuyuki RT, Varney J, Johnson JA. A meta-analysis of the association between adherence to drug therapy and mortality. BMJ. 2006;333:15.

23. Patel MR, Mahaffey KW, Garg J, Pan G, Singer DE, Hacke W, Breithardt G, Halperin JL, Hankey GJ, Piccini JP, Becker RC, Nessel CC, Paolini JF, Berkowitz SD, Fox KA, Califf RM. Rivaroxaban versus warfarin in nonvalvular atrial fibrillation. N Engl J Med. 2011;365:883-91.

24. Suarez C, Pose A, Montero-Perez-Barquero M, Roquer J, Gállego J, Ràfols C, Cazorla D, Vivancos J. Validation of satisfaction questionnaire acts in outpatients with atrial fibrillation treated with oral anticoagulants in Spain. Aladin study. Med Clin (Barc). 2016;147:192-8.

25. Cano SJ, Lamping DL, Bamber L, Smith S. The anticlot treatment scale (ACTS) in clinical trials: crosscultural validation in venous thromboembolism patients. Health Qual Life Outcomes. 2012;10:120.

26. Atkinson MJ, Sinha A, Hass SL, Colman SS, Kumar RN, Brod M, Rowland CR. Validation of a general measure of Treatment satisfaction, the Treatment Satisfaction Questionnaire for Medication (TSQM, using a national panel study of chronic disease. Health Qual Life Outcomes. 2004;2:12.

27. Atkinson MJ, Kumar R, Cappelleri JC, Hass SL. Hierarchical construct validity of the treatment satisfaction questionnaire for medication (TSQM version ii) among outpatient pharmacy consumers. Value Health. 2005;8(Suppl 1):S9-24.

28. Coleman CI, Coleman SM, Vanderpoel J, Nelson W, Colby JA, Scholle JM, Kluger J. Patient satisfaction with warfarin- and non-warfarin-containing thromboprophylaxis regimens for atrial fibrillation. J Investig Med. 2013;61:878-81. 
29. Samsa G, Matchar DB, Dolor RJ, Wiklund I, Hedner E, Wygant G, Hauch O, Marple CB, Edwards R. A new instrument for measuring anticoagulation-related quality of life: development and preliminary validation. Health Qual Life Outcomes. 2004;2:22.

30. Patel MR, Hellkamp AS, Lokhnygina Y, Piccini JP, Zhang Z, Mohanty S, Singer DE, Hacke W, Breithardt G, Halperin JL, Hankey GJ, Becker RC, Nessel CC, Berkowitz SD, Califf RM, Fox KA, Mahaffey KW. Outcomes of discontinuing rivaroxaban compared with warfarin in patients with nonvalvular atrial fibrillation: analysis from the ROCKET AF trial (rivaroxaban once-daily, oral, direct factor xa inhibition compared with vitamin $\mathrm{k}$ antagonism for prevention of stroke and embolism trial in atrial fibrillation). J Am Coll Cardiol. 2013;61:651-8.

31. Lancaster TR, Singer DE, Sheehan MA, Oertel LB, Maraventano SW, Hughes RA, Kistler JP. The impact of long-term warfarin therapy on quality of life. Evidence from a randomized trial. Boston area anticoagulation trial for atrial fibrillation investigators. Arch Intern Med. 1991;151:1944-9.

32. Gage BF, Cardinalli AB, Owens DK. The effect of stroke and stroke prophylaxis with aspirin or warfarin on quality of life. Arch Intern Med. 1996;156:1829-36.

33. Osterberg L, Blaschke T. Adherence to medication. N Engl J Med. 2005;353:487-97.

34. Yao X, Abraham NS, Alexander GC, Crown W, Montori VM, Sangaralingham LR, Gersh BJ, Shah
ND, Noseworthy PA. Effect of adherence to oral anticoagulants on risk of stroke and major bleeding among patients with atrial fibrillation. J Am Heart Assoc. 2016;5:e003074.

35. Jackevicius CA, Tsadok MA, Essebag V, Atzema C, Eisenberg MJ, Tu JV, Lu L, Rahme E, Ho PM, Turakhia M, Humphries KH, Behlouli H, Zhou L, Pilote L. Early non-persistence with dabigatran and rivaroxaban in patients with atrial fibrillation. Heart. 2017;103:1331-8.

36. Brown JD, Shewale AR, Talbert JC. Adherence to rivaroxaban, dabigatran, and apixaban for stroke prevention in incident, treatment-naive nonvalvular atrial fibrillation. J Manag Care Spec Pharm. 2016;22:1319-29.

37. McHorney CA, Crivera C, Laliberte F, Nelson WW, Germain G, Bookhart B, Martin S, Schein J, Lefebvre $\mathrm{P}$, Deitelzweig S. Adherence to non-vitamin-k-antagonist oral anticoagulant medications based on the pharmacy quality alliance measure. Curr Med Res Opin. 2015;31:2167-73.

38. Shore S, Carey EP, Turakhia MP, Jackevicius CA, Cunningham F, Pilote L, Bradley SM, Maddox TM, Grunwald GK, Barón AE, Rumsfeld JS, Varosy PD, Schneider PM, Marzec LN, Ho PM. Adherence to dabigatran therapy and longitudinal patient outcomes: insights from the Veterans health administration. Am Heart J. 2014;167:810-7. 